\title{
Lubrication Performance Improvements on Two Side-Surfaces of Crescent Board in Internal Involute Gear Pump
}

\author{
Ren Zhenxing ${ }^{*}, 1$, Liu Chunyan ${ }^{2}$ and Li Yulong ${ }^{1}$ \\ ${ }^{1}$ Industrial Manufacturing School, Chengdu University, Chengdu, Sichuan 610106, China \\ ${ }^{2}$ Safety, Environment \& Technology Supervision Research Institute, PetroChina Southwest Oil \& Gasfield Company, \\ Chengdu, Sichuan 610041, China
}

\begin{abstract}
To improve the oil film force for enhancing lubrication effect and reducing wear and increasing service life within radial friction pair of internal involute gear pump, the oil wedge for hydrodynamic lubrication effect was the better solution. On the basis of related theory of hydrodynamic lubrication, from the two arc surfaces adjustment of crescent board inside and outside, the current parallel radial gaps were made into non-parallel radial convergence gaps with oil wedge structure for hydrodynamic lubrication effect, so the current single hydrostatic lubrication state would be changed into the combination state with hydrostatic lubrication and hydrodynamic lubrication. In the case of the radial gap on the inside arc surface of crescent board as a example, From the maximum oil film force conditions, the best convergence ratio of inside radial gap could be derived, and then the new center position and new radius value of inside adjusted arc contour of crescent board were calculated. All results indicated that, after the current parallel radial gaps were replaced by the nonparallel radial best convergence gap, the oil film force and the volumetric efficiency of pump would be significantly improved, under the case parameters, the best convergence rate with the initial pressure difference of $1.9 \mathrm{MPa}$ was 0.96 , but the corresponding best convergence rate without the initial pressure difference was about 1.2 , at the same time, the oil film force was increased by $92.4 \%$, the liquid flow rate brought into the discharge oil cavity from the absorption oil cavity of pump was increased by $30.2 \%$; at the same time, the higher the driving speed and the thinner the minimum oil film thickness and the lower the discharge oil pressure is, the greater the best convergence ratio and the bigger the oil film force or the increase of the oil film force and the higher the pump volume efficiency and the more obvious the hydrodynamic lubrication effect and the greater the liquid flow rate brought into the discharge oil cavity from the absorption oil cavity of pump is, it could be said that the higher the driving speed was, the more obvious the hydrodynamic lubrication effect, but the less obvious the hydrostatic lubrication effect, in contrast with this, the higher the discharge oil pressure was, the more obvious the hydrostatic lubrication effect, but the less obvious the hydrodynamic lubrication effect; because the adjustment value of the inside arc contour of crescent board was smaller, in practical application, these factors such as manufacturing error and elastic deformation and thermal deformation must be comprehensively involved in the oil wedge structure design. Finally, the important conclusions are obtained that the design method of oil wedge structure on the inside and outside arc surface of crescent board is proved feasible, as for other such as straight line conjugate internal gear pump with crescent board, the relevant content of this paper also can be used for its oil wedge structure design, but because of oil wedge structure, so the design method of oil wedge structure of radial gap only $\mathrm{b}$ appropriate for one-way internal gear pump.
\end{abstract}

Keywords: Crescent board, hydrodynamic lubrication effect, internal gear pump, oil film force, radial gap.

\section{INTRODUCTION}

The internal involute gear pump (referred to as the internal gear pump) is a pumping oil hydraulic components, has the stable conveying, low noise, long life and other advantages, and is widely applied $[1,2]$, Many researches on the pump are reported [3-8]. There are many friction pairs on of the inner meshing pump, there failures have great relevance the whole failures, the failure probability of the friction pair formed crescent plate and the inner and outer gear pump is relatively high [9], the gap is large, it can increase the leakage loss, volumetric efficiency decreased the gap; when it is small, it would happen to the so-called "scraper" phenomenon. Therefore, automatic compensation is very necessary [10-13]. It is given in reference [14] that optimization design method of the radial clearance, it is studied in the literature [15] angle radial compensation of crescent plate.

From the theory of friction and lubrication, good lubrication condition can effectively reduce the friction pair of wear and improve the life of the pump, and dynamic lubrication effect is one of the main form to improve the lubrication state, the speed higher, the effect more apparent [16]. At present, there are many literatures and patents about by improving the material to improve the lubrication performance [17-19]; In addition, by building a model of 
converging oil wedge structure, make the gap in the oil film bearing capacity (hereinafter referred to as the oil film force) increased significantly, so as to achieve good dynamic lubrication effect [16]. Therefore, this paper puts forward a kind of improved link on both sides of the dynamic pressure lubrication effect of the internal gear pump.

\section{THE RADIAL FRICTION PAIR OF LINK ON BOTH SIDES}

Internal gear pump is adopted the gear meshing theory as shown in Fig. (1), internal gear1 and external gear 3 close to the side of the pitch circle, the other side is separated from the " link 4"on the pump cover. The internal gear 1 on driving shaft drives external gear 3 which rotate in the same direction, in the oil suction mouth gear separated form the negative pressure and suction liquid, the gears mesh with pressure oil mouth constantly embedded and liquid extrusion output [20]. Fig. (1a), $\mathrm{o}_{1}, \mathrm{o}_{2}$ for internal and external gear center, $\omega_{1}, \omega_{2}$ for inside and outside gear rotating angular velocity, $\mathrm{rad} / \mathrm{s}$. Among them, the link contact with internal gear addendum circle surface through its inner surface the outer surface and external gears addendum circle contact surface, the space between the outside and internal gear are split into two independent seal, oil absorption cavity 2 and 7 in the pressure oil chamber. Here is not really mean zero clearance on contact. Considering the needs of the internal and external gear rotating and errors of processing, assembly, there must be some certain gap.

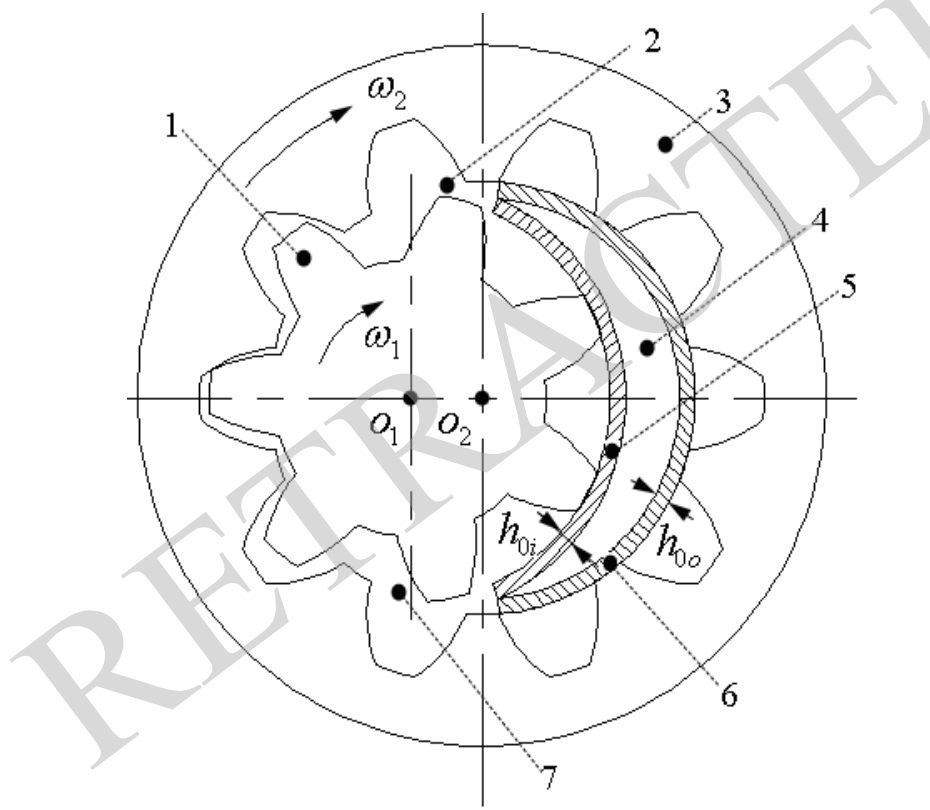

Note: sign 1 indicates internal gear or driving gear; sign 2 indicates the absorption oil cavity of pump; sign 3 indicates external gear or driven gear; sign 4 indicates the crescent board; sign 5 indicates the inside gap of crescent board; sign 6 indicates the outside gap of crescent board; sign 7 indicates the discharge oil cavity of pump; sign $o_{1}$ indicates the circle center of driving gear; sign $o_{2}$ indicates the circle center of driven gear; sign $\omega_{1}$ indicates the rotational speed of driving gear, $\mathrm{rad} / \mathrm{s}$; sign $\omega_{2}$ indicates the rotational speed of driven gear, $\mathrm{rad} / \mathrm{s}$; sign $h_{0 i}$ indicates the radial gap between the inside surface of crescent board and addendum circle surface of driving gear, $\mathrm{m}$; sign $h_{0 o}$ indicates the radial gap between the outside surface of crescent board and addendum circle surface of driven gear, $\mathrm{m}$, similarly hereinafter.

Fig. (1). The internal involute gear pump and the inside radial gap and outside radial gap of crescent board.
Radial distance of from medial surface of the link and internal gear tooth top round surface is called internal oil film clearance, as shown in Fig. (1) of $\mathrm{h}_{0 \mathrm{i}}$, radial distance of from medial surface of the link and external gear tooth top round surface is called internal oil film clearance, as shown in Fig. (1) of $\mathrm{h}_{00}$.

Liquid in the inside and outside the oil film clearance, on the one hand on, under the action of pressure difference of oil and oil absorption results in leakage from high pressure side to low side, on the other hand, caused by the circumferential speed of the internal and external gears addendum circle of viscous friction, a small number of liquid from the suction side was taken to the oil pressure side.

\section{THE OIL WEDGE STRUCTURE ON BOTH SIDES OF LINK}

To avoid scraper phenomenon on the top of the internal and external gear tooth, link on both sides of the oil film force wants the bigger the better [21], so, under the same action of external force, the minimum oil film thickness can be appropriately increased, the lubrication effect is greatly improved. In the current design such as clearance, because without considering the oil film in the dynamic pressure effect, so the oil film force is relatively small. If through link profile adjustment on both sides, make the link both has the convergence between oil wedge structure, as shown in Fig. (2). Among them, the convergence on either side of the gap in the oil suction side has a maximum value $h_{2 i}, h_{2 o}, \mathrm{~m}$, In the pressure side with the minimum $h_{l i}, h l o, \mathrm{~m}$. Note: the clearance value is very small in the figure, to exaggerate the illustration is easy to describe.

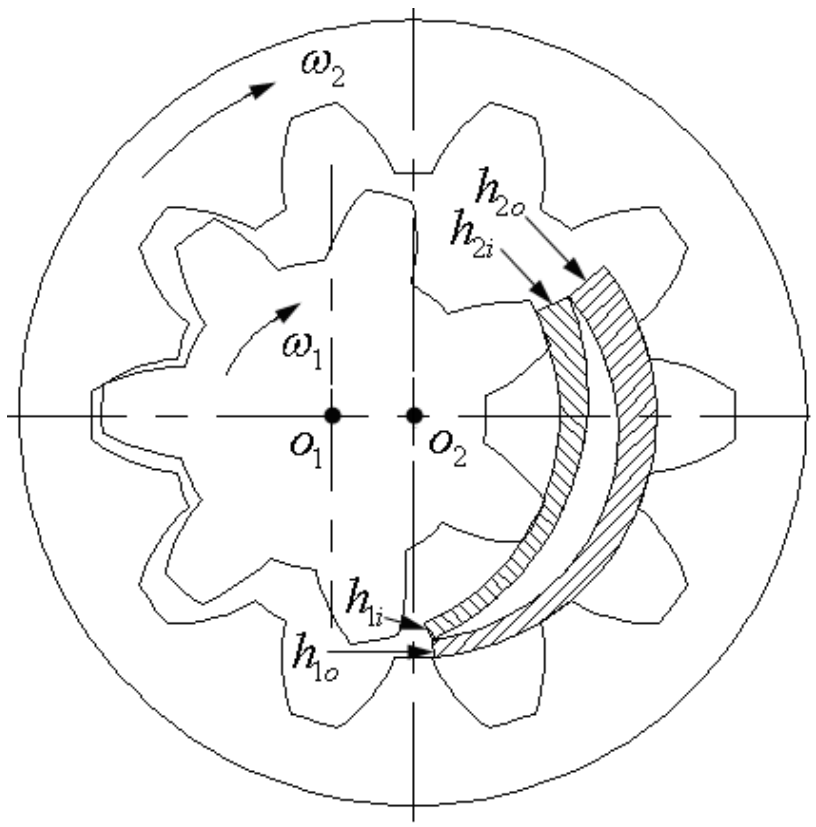

Note: sign $h_{1 i}$ indicates the minimum value of inside radial convergent gap of crescent board, m; sign $h_{2 i}$ indicates the maximum value of inside radial convergent gap of crescent board, m; sign $h_{1 o}$ indicates the minimum value of outside radial convergent gap of crescent board, m; sign $h_{2 o}$ indicates the maximum value of outside radial convergent gap of crescent board, $\mathrm{m}$, similarly hereinafter.

Fig. (2). The inside radial convergent gap and outside radial convergent gap of crescent board. 
Inside and outside the oil wedge structure of requirements of the link as shown in Fig. (2), along the circumferential direction of each, as shown in Fig. (3) is formed inside and outside oil wedge inclined planes, the two inclined planes are in accord with the infinite slope slide block related tribology theory [16].

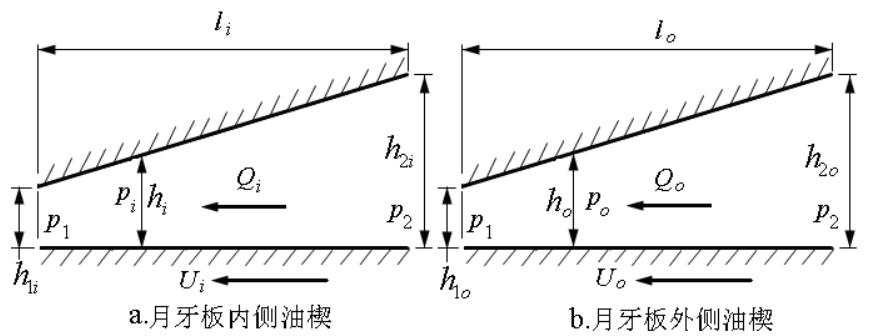

a. The inside oil wedge structure $\quad b$. The outside oil wedge structure of crescent board of crescent board

Note: sign $U_{i}$ and sign $U_{o}$ indicate the addendum movement speed of driving gear and driven gear, $\mathrm{m} / \mathrm{s}$; sign $l_{i}$ and sign $l_{o}$ indicate the inside sealing area length and the outside sealing area length of crescent board, $\mathrm{m}$; sign $p_{1}$ and sign $p_{2}$ indicate the discharge oil pressure and absorption oil pressure, $\mathrm{Pa}$; sign $Q_{i}$ and sign $Q_{o}$ indicate the inside and outside liquid flow brought into discharge cavity from absorption cavity of pump, $\mathrm{m}^{3} / \mathrm{s} ; \operatorname{sign} h_{i}$ and sign $h_{o}$ indicate the inside and outside gap value of crescent board under a certain position, $\mathrm{m}$; sign $p_{i}$ and sign $p_{o}$ indicate the inside and outside oil film pressure of crescent board under a certain position, $\mathrm{Pa}$, similarly hereinafter.

Fig. (3). The two oil wedge structures on inside and outside surface of crescent board.

In Fig. (3), $U_{i}, U_{o}$ for internal and external gears addendum movement speed, $\mathrm{m} / \mathrm{s}, 1_{\mathrm{i}}, \mathrm{l}_{\mathrm{o}}$ for the lateral sealing area lengths of internal and external gear with link respectively, $\mathrm{m} ; \mathrm{P}_{1}$ and $\mathrm{p}_{2}$ for pressure pump pressuring oil and oil suction pressure, $\mathrm{Pa} . \mathrm{Q}_{\mathrm{i}}$ and $\mathrm{Q}_{\mathrm{o}}$ for liquid flows of the link within the medial and lateral oil film clearance by the oil suction side into the oil to the pressure side, $\mathrm{m}^{3} / \mathrm{s}$, the greater the value, the higher the volumetric efficiency of pump; $\mathrm{H}_{\mathrm{i}}, \mathrm{h}_{\mathrm{o}}(\mathrm{m})$ and $\mathrm{P}_{\mathrm{i}}, \mathrm{P}_{\mathrm{o}}(\mathrm{Pa})$ for link medial, lateral oil film clearance under a certain position within the oil film clearance and oil film pressure, the oil film pressure. The greater the oil film force, the greater the minimum oil film clearance is needed to the smaller [16].

\section{THE INSIDE OIL FILM FORCE OF LINK AND FLOW}

Due to the same design of the oil wedge structure of the link internal and external sides, in this paper, just take inside structure as example and combine with the literature [22, 23], based on the lubrication theory of infinite slope slide block [16], by deduction, get under the initial pressure difference $\Delta \mathrm{p}=\mathrm{p}_{1}-\mathrm{p}_{2}(\mathrm{~Pa})$, the expressions for the pressure inside the slope slide block distribution.

$$
p_{i}=\frac{6 U_{i} \mu l_{i}}{h_{1 i} K_{i}}\left[\begin{array}{l}
\frac{1}{h_{i}}+\frac{h_{i p}}{4}\left(\frac{1}{h_{2 i}^{2}}+\frac{1}{h_{1 i}^{2}}\right) \\
-\frac{h_{i p}}{2 h_{i}^{2}}-\frac{1}{2}\left(\frac{1}{h_{2 i}}+\frac{1}{h_{1 i}}\right)
\end{array}\right]+\frac{p_{2}+p_{1}}{2}
$$

In formula, $\mu$ as the fluid viscosity, Pa.s; $\mathrm{K}_{\mathrm{i}}=\mathrm{h}_{2 \mathrm{i}} / \mathrm{h}_{1 \mathrm{i}}-1$ as the convergence of the medial oil wedge ratio of link; $h_{i p}$ for the maximum pressure of oil film thickness, $\mathrm{m}$, in $\mathrm{p}_{1}=\mathrm{p}_{2}$
$=0$, formula (1) and literature [16] has the same formula given.

By the maximum pressure in the oil film, there exists $\mathrm{dpi} / \mathrm{dhi}=0$, so

$$
h_{i p}=2 h_{1 i} \frac{K_{i}+1}{K_{i}+2}-\frac{h_{1 i}^{3}\left(K_{i}+1\right)^{2}}{3 U_{i} \mu l_{i}\left(K_{i}+2\right)} \Delta p
$$

In $\mathrm{p} 1=\mathrm{p} 2=0$, namely $\Delta \mathrm{p}=0$, formula (2) and literature [16] has the same formula given.

Integrating formula (1) the pressure distribution along the link shown in the width direction, get the the oil film force $\mathrm{W}_{\mathrm{i}}(\mathrm{N})$ of of the inside of link:

$W_{i}=\frac{B l_{i}}{h_{1 i} K_{i}} \int_{h_{1 i}}^{h_{2 i}} p_{i} \mathrm{~d} h_{i} \approx \frac{B l_{i}}{M} \sum_{j=1}^{M} p_{i}(j)$

In the formula (3), B is the width of the link, $\mathrm{m}$; $\mathrm{M}$ for integral iteration steps.

Through the inside oil film clearance of link, from oil suction side to flow pressure oil side, the liquid flow (hereinafter referred to as) $\mathrm{Q}_{\mathrm{i}}(\mathrm{m} 3 / \mathrm{s})$ :

$$
Q_{i}=Q_{\omega 1}-Q_{\Delta p}=r_{a 1} \omega_{1} B h_{1 i} \frac{K_{i}+1}{K_{i}+2}-\frac{B h_{1 i}^{3}\left(K_{i}+1\right)^{2}}{6 \mu l_{i}\left(K_{i}+2\right)} \Delta p
$$

in the formula (4), $\mathrm{Q}_{\mathrm{w} 1}$ for shear flow, $\mathrm{m} 3 / \mathrm{s}$, the larger the value, the volumetric efficiency of the pump is higher; $Q_{\Delta p}$ for differential flow caused by differential pressure $\Delta \mathrm{p}, \mathrm{m} 3 /$ $\mathrm{s}$, the larger the value, the lower the volumetric efficiency of pump, $\mathrm{r}_{\mathrm{a} 1}$ for internal gear addendum circle radius, $\mathrm{m}$.

\section{THE EXAMPLE COMPUTATION AND ANALYSIS}

In the example, the parameters are as follows: modulus of 3 $\mathrm{mm}$, internal gear tooth number of 10 , external gear teeth of 16 , pitch circle pressure angle of $20^{\circ}$, meshing angle of pitch circle of $25^{\circ}$, tooth of $20 \mathrm{~mm}$ wide, $\mathrm{l}_{\mathrm{i}}=0.5 \mathrm{PI} \mathrm{ra1}, \mathrm{h}_{0 \mathrm{i}}$ $=\mathrm{h}_{1 \mathrm{i}}=0.03 \mathrm{~mm}, \mathrm{p}_{1}=2 \mathrm{MPa}, \mathrm{p}_{2}=0.1 \mathrm{MPa}$, speed $\mathrm{n}_{1}=6000$ $\mathrm{RPM}$, viscosity $0.0262 \mathrm{~Pa}$. $\mathrm{s}, \mathrm{M}=10000$. At this point, with $\left(\mathrm{K}_{\mathrm{i}}>0\right)$ or no $\left(\mathrm{K}_{\mathrm{i}}=0\right)$ oil wedge structure, the oil film force of the inside of link and flow change with convergence $\mathrm{K}_{\mathrm{i}}$ as shown in Fig. (4).

In Fig. (4a), for $p_{1}=p_{2}=0$ without initial pressure difference, the best convergence ratio is 1.188 that is close to 1.2 , which is completely consistent to the given value of 1.2 of the related literature [16] and illustrates the formula (1) (4) the correctness of the derived. For $\mathrm{p}_{1}=2 \mathrm{MPa}, \mathrm{p}_{2}=0.1$ MPa with initial pressure differential case, and under the best convergence $\mathrm{K}_{\mathrm{i}}=0.96$, the oil film force is $1172.7 \mathrm{~N}$, the flow is $4.01 \times 10^{-6} \mathrm{~m}^{3} / \mathrm{s}$. And in parallel with the same minimum clearance within the oil film force, namely, at the position where $\mathrm{K}_{\mathrm{i}}=0$, oil film force is $609.5 \mathrm{~N}$, the flow is $3.08 \times 10-6 \mathrm{~m} 3 / \mathrm{s}$. Thus, the oil film force (1172.7-609.5) / 609.5 material $92.4 \%$ is improved, the dynamic pressure effect makes the lubrication performance is better; the flow of inside increased (4.01-3.08) / 4.01 $\approx 30.2 \%$, which makes the pump volume efficiency is higher.

Without considering manufacturing installation error and elastic deformation during works and the thermal deformation caused by clearance changes under the 
condition of $[16,24-26]$, once confirmed the link under a certain condition gets the best convergence of the medial convergence gap, so it can proceed to link the inside dimensions of design calculation, as shown in Fig. (5). It is mainly concerned with the $o_{1}$ from its center $o_{i}$ link inside dimensions to the internal gear circle eccentricity $e_{i}$ and arc radius $r_{\mathrm{ai}}$.
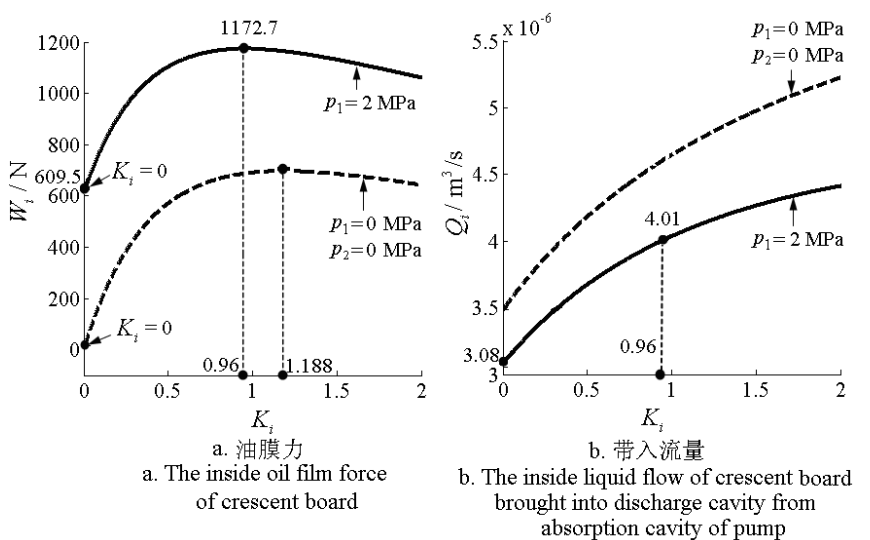

Note: sign $W_{i}$ indicates the inside oil film force of crescent board, N; sign $Q_{i}$ indicates the inside liquid flow of crescent board brought into discharge cavity from absorption cavity of pump, $\mathrm{m}^{3} / \mathrm{s}$; sign $K_{i}$ indicates the convergence ratio of inside radial convergent gap of crescent board, similarly hereinafter.

Fig. (4). Inside Oil film force and inside liquid flow of crescent board brought into discharge cavity from absorption cavity of pump.

In Fig. (5), the triangle $\Delta \mathrm{o}_{\mathrm{i}} \mathrm{O}_{1} \mathrm{i}$ and triangle $\Delta \mathrm{o}_{\mathrm{i}} \mathrm{O}_{1} \mathrm{O}$, exist the following geometric relationships:

$r_{a i}^{2}=e_{i}^{2}+\left(r_{a 1}+h_{2 i}\right)^{2}-2 e_{i}\left(r_{a 1}+h_{2 i}\right) \sin \alpha_{2 i}$

and

$r_{a i}^{2}=e_{i}^{2}+\left(r_{a 1}+h_{1 i}\right)^{2}+2 e_{i}\left(r_{a 1}+h_{1 i}\right) \sin \alpha_{1 i}$

In type, the $\alpha_{1 i}$ as the angle that the sealing area of link in oil pump pressure side, rad. $\alpha_{2 \mathrm{i}}$ as the angle that the sealing area in the pump suction side, rad, they are all the values of basic parameters for pump. then

By type (5) is equal to (6), and take the $\alpha_{1 i}=\alpha_{2 i}=45^{\circ}$,

$e_{i}=0.5 K_{i}^{*} h_{1 i} / \sin \alpha_{1 i}$

$=0.5 \times 0.96 \times 0.03 / 0.707 \approx 0.01 \mathrm{~mm}$

Take the $\mathrm{e}_{\mathrm{i}}$ into type (5) or (6), can obtain the corresponding arc radius $\mathrm{r}_{\mathrm{ai}} \approx 18.53 \mathrm{~mm}$; And $\mathrm{r}_{\mathrm{a} 1} \approx 18.48 \mathrm{~mm}$. The $e_{i}$ value is small, here is caused by the samll value $h_{1 i}$. Practices have proved that in the design of oil wedge structure of convergence, for installing and manufacturing errors, elastic deformation and thermal deformation of the gap caused by the change, often are more than the value of minimum oil film thickness, which, therefore, it is necessary to consider the impact of these factors [16]. The processing method can refer to the [27].

When rotation speed is 2000 RPM, 3000 RPM and 4000 RPM, and the other parameters are fixed, the oil film force and flow of the inside link change with the convergence ratio, as shown in Fig. (6). Thus, the higher the speed, the best convergence ratio, the greater the oil film force and into the flow. The greater the dynamic pressure effect makes the lubrication performance of inside link better, the higher the pump volume efficiency.

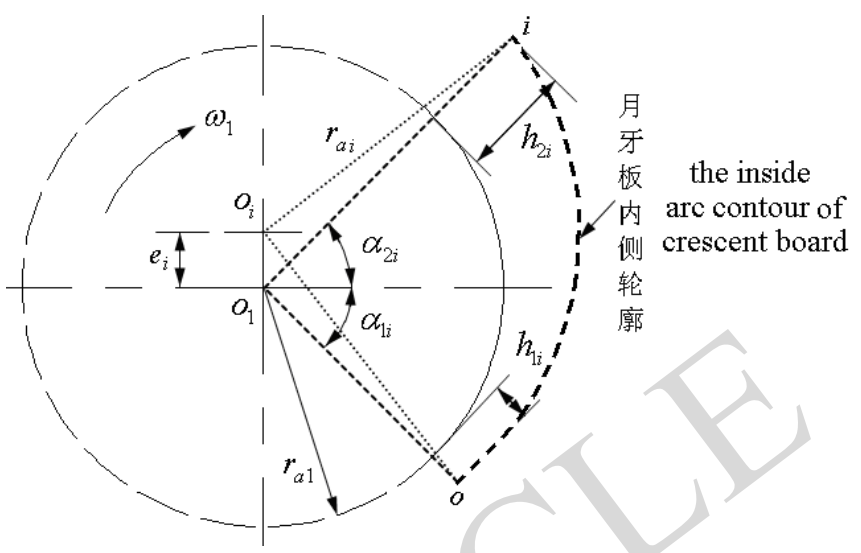

Note: sign $i$ indicates the starting point of inside radial convergent gap of crescent board; sign $o$ indicates the end point of inside radial convergent gap of crescent board; sign $r_{a 1}$ indicates the addendum circle radius of driving gear, $\mathrm{m}$; sign $r_{a i}$ indicates the inside arc radius with radial convergent gap of crescent board, $\mathrm{m}$; sign $o_{i}$ indicates the inside arc center with radial convergent gap of crescent board; sign $e_{i}$ indicates the distance from point $o_{i}$ to point $o_{1}, \mathrm{~m}$; sign $\alpha_{1 i}$ indicates the corresponding angle of inside sealing area of crescent board in discharge cavity of pump, rad; sign $\alpha_{2 i}$ indicates the corresponding angle of inside sealing area of crescent board in absorption cavity of pump, rad, similarly hereinafter.

Fig. (5). The arc contour design of crescent board with inside radial convergent gap.
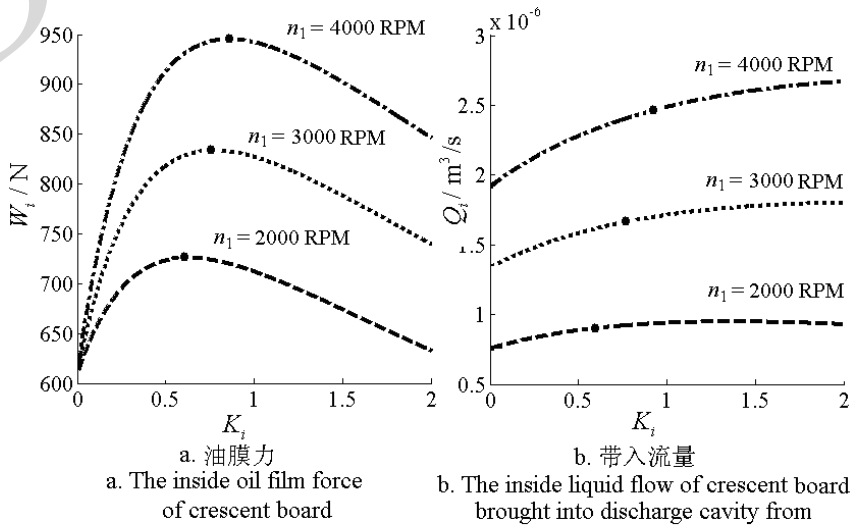

b. The inside liquid flow of crescent board brought into discharge cavity from absorption cavity of pump

Note: sign $n_{1}$ indicates the rotating speed of driving gear, RPM, similarly hereinafter.

Fig. (6). Inside oil film force and inside liquid flow of crescent board brought into discharge cavity from absorption cavity of pump in different rotating speeds.

When the minimum oil film clearance is $0.03 \mathrm{~mm}, 0.05$ $\mathrm{mm}$ and $0.07 \mathrm{~mm}$ respectively, and the other parameters are fixed, the oil film force and flow of the inside link change with the convergence ratio, as shown in Fig. (7). Thus, the minimum oil film clearance is smaller, the best convergence ratio, the greater the oil film force and into the flow, the greater the dynamic pressure effect makes the lubrication performance better, the higher the pump volume efficiency.

When the pump oil pressure $\mathrm{p}_{1}$ is $1 \mathrm{MPa}, 3 \mathrm{MPa}, 5 \mathrm{MPa}$, respectively, and the other parameters constant, the oil film force and flow of the inside link, change with the 
convergence ratio, as shown in Fig. (8). $\mathrm{P}_{1}=1 \mathrm{MPa}$, will use the best convergence than the period of the oil film force for $(604-320)$ / 604 88.8\%; $\quad \mathrm{P}_{1}=3 \mathrm{MPa}, \quad(1072-900)$ $1900 \approx 19.1 \% ; \mathrm{P}_{1}=5 \mathrm{MPa},(1571-1480) / 1480 \approx 6.1 \%$. Thus, the lower the pressure of oil, the best convergence ratio, the greater the oil film force and flow, dynamic pressure effect makes the lubrication performance of the inside link is better, and capacity efficiency of pump is higher.

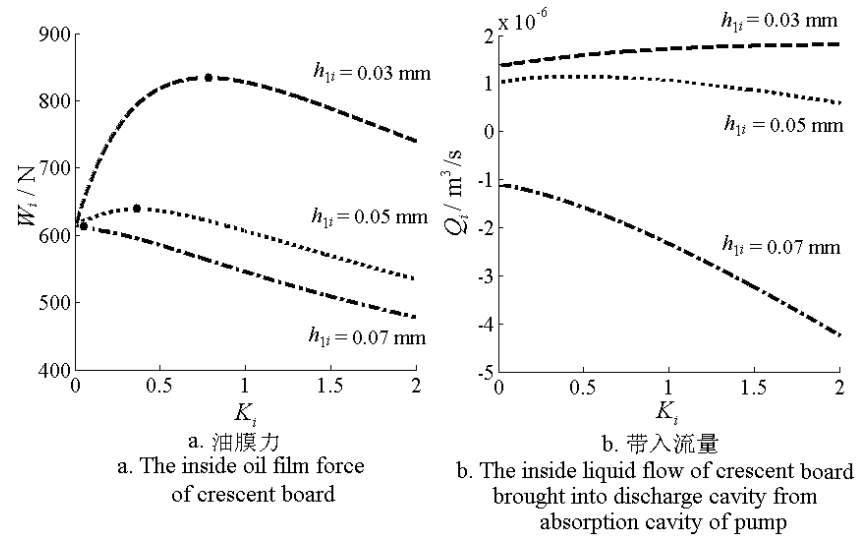

Fig. (7). Oil film force and the inside liquid flow of crescent board brought into discharge cavity from absorption cavity of pump in different minimum oil film thickness.
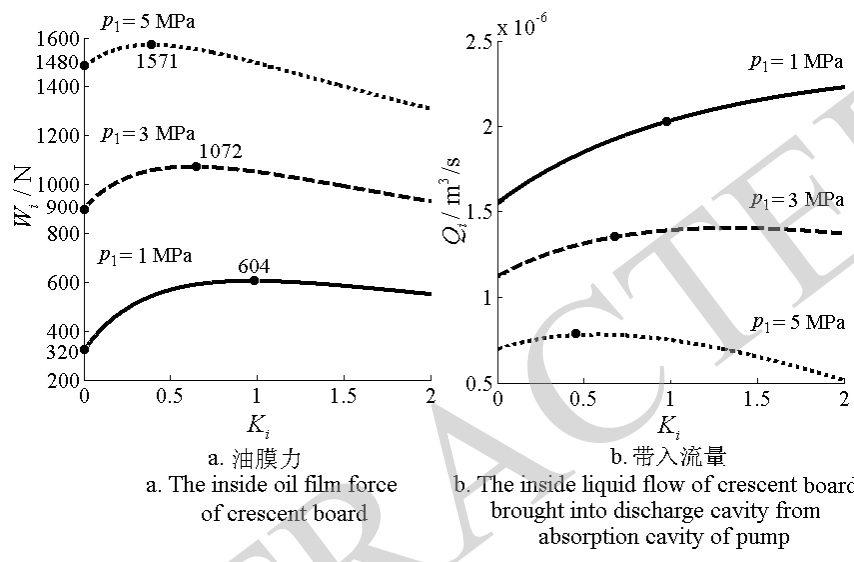

Fig. (8). Oil film force and the inside liquid flow of crescent board brought into discharge cavity from absorption cavity of pump in different discharge oil pressure.

The lateral oil wedge structure of the link can be completely designed referring to the inside, relevant conclusions are also the same. In addition, because the link exists the oil wedge structures on both sides, this paper applies only to one-way internal gear pump. As for other such as straight line conjugate internal gear pump with link, also can use the relevant content of this paper, to the oil wedge structure design on both sides of link.

\section{CONCLUSION}

(1) Link on both sides of the parallel structure of radial clearance adjustment for the oil wedge best convergence gap, the oil film force and the volumetric efficiency of the pump are improved. By using the case parameters, the oil film force of inside of the link increased by $92.4 \%$, from the oil suction side to pressure oil side liquid flow rate increased by $30.2 \%$.
(2) The higher the speed, the smaller the minimum oil film clearance and the lower the pressure oil pressure, the best convergence ratio, the greater the oil film force or the oil film force period and into the flow, the greater the dynamic lubrication effect is more apparent, the higher the pump volume efficiency.

(3) The paper only discusses the design method of convergence oil wedge structure on both sides of the link. In practical, the need to consider installation of manufacturing error, elastic deformation and thermal deformation of work and the influence of such factors. And because there are a bilateral link oil wedge structure, it is only applicable to one-way internal gear pump.

\section{CONFLICT OF INTEREST}

The authors confirm that this article content has no conflict of interest.

\section{ACKNOWLEDGEMENTS}

\section{Declared none. \\ REFERENCES}

[1] Y. L. Li, "Mechanism modeling and experiment Investigation of trapped oil in external gear pump," (in Chinese with English abstract), Hefei University of Technology: Hefei, 2009.

[2] Z. Wang, "Internal gear pump research hot spot and tendency," Farm Machinery, vol. 29, no.5, pp.76-77, 2008.

[3] H. Sasaki, N. Inui, Y. Shimada, and D. Ogata, "Development of high Efficiency $\mathrm{P} / \mathrm{M}$ internal gear pump rotor," Automotive SEI Technical Review, vol. 66, pp.124-128, 2008.

[4] S. Y. Jung, M. S. Kim, H. Y. Cho, and C. Kim, "Development of an automated design system for oil pumps with multiple profiles circle, ellipse, and involute," Journal of the Korean Society for Precision Engineering, vol. 26, no. 3, pp. 103-112, 2009.

[5] Y. Inaguma, "Friction torque characteristics of an internal gear pump," In: Proceedings of the Institution of Mechanical Engineers, Part C: Journal of Mechanical Engineering Science, vol. 225, no. 6, pp. 1523-1534, 2011.

[6] T. H. Choi, M. S. Kim, G. S. Lee, S. Y. Jung, J. H. Bae, and C. Kim, "Design of rotor for internal gear pump using cycloid and circular-arc curves," Journal of Mechanical Design, vol. 134, no. 1, pp. 011005-1-011005-12, 2012.

[7] J. Luo, S. Wu, and Z. Yuan, "Design and manufacture of water hydraulic internal gear pump," Journal of Nanjing University of Science and Technology, vol. 30, no.6, pp. 692-696, 2006. (in Chinese with English abstract)

[8] Y. Li, and L. Yang, "Development and test of an in ternal gear pump group used for high temperature, high speed and large flow," Transactions of the CSAM, vol. 31, no. 3, pp. 77-80, 2000. (in Chinese with English abstract)

[9] W. Zhang, and F. Rui, "Failure Analysis on Gear Pump," Fluid Power Transmission and Control, vol. 8, no.1, pp. 26-28, 2005.

[10] H. Li, L. Cui, and X. Cheng, "Flexibility analysis of gear shaft of internal gear pumps," Machine Tool \& Hydraulics, vol. 37, no. 9, pp. 116-118, 2009. (in Chinese with English abstract)

[11] J. Zhang, and K. Li, "Study on hydrostatic support of inner gear in inner mesh gear pumps," China Mechanical Engineering, vol. 22, no. 13, pp. 1532-1536, 2011. (in Chinese with English abstract).

[12] G. Zhang, "The high-pressure internal gear pump," Fluid Power Transmission and Control, vol. 49, no. 6, pp. 57-58, 2011.

[13] X. Li, "One Kind of Gap Compensation Structure of Internal Gear Pump," China, 201120474999, 2012, pp. 9-12.

[14] J. Wu, and M. Liao, "The optimal gap between small gear's addendum and crescent shaped link of the internal involute gear pump," Machine Tool \& Hydraulics, vol. 39, no. 5, pp. 34-35, 2011, (in Chinese with English abstract). 
[15] Z. Hao, J. Zhang, and K. Li, "Study on the angle of stationary crescent of radial compensation for inner mesh gear pump," Mechanical Transmission, vol. 36, no. 6, pp. 8-14, 2012. (in Chinese with English abstract)

[16] S. Wen, and P. Huang, The principle of Tribology, Tsinghua University Press: Beijing, 2008.

[17] W. Xu, Y. YIin, and Q. Tian, "Tribological properties of the Fe based gear pump side plate prepared by power metallurgy method," Power Metallurgy Industry, vol. 21, no. 3, pp. 20-23, 2011. (in Chinese with English abstract)

[18] W. Shen, "The use of gear pump for continuous casting of copper alloy plate," China, 201110360789, pp. 2-22, 2012

[19] X. Xu, "A gear pump gear side end face wear resistance," China, 200810224087, 2009-02-18

[20] C. He, Hydraulic Components, Beijing: China Machine Press, 1985, (in Chinese)

[21] G. Yao, "Analysis of oil film force of meshing tooth gear involute few teeth difference internal," Journal of East China University of Science and Technology, vol. 11, no. 1, pp. 121-127, 1985.

[22] L. Wang, "Analysis of static and dynamic characteristics on spiral oil wedge hydrodynamic bearing considering input pressure,"
Lubrication Engineering, vol. 33, no. 11, pp. 77-80, 2008. (in Chinese with English abstract)

[23] Y. Li, and K. Liu, "Study of lubricating state on meshing surface in external gear lubrication pump without regard to trapped volume," Lubrication Engineering, vol. 33, no. 5, pp. 42-45, 2008. (in Chinese with English abstract)

[24] S. Chen, and C. Lu, "The analysis of structure on a novel spiral oil wedge hybrid Journal Bearing," Lubrication Engineering, vol. 182, no. 10, pp. 15-21, 2006. (in Chinese with English abstract)

[25] Q. Bi, J. Ling, and C. Zhang, "Analysis on structure feature of IGP high pressure low noise internal gear pumps," Machine Tool \& Hydraulics, vol. 38, no.2, pp. 50-52, 2010. (in Chinese with English abstract)

[26] B. Paffoni, R. Progri, and R. Gras, "Teeth clearance effects upon pressure and film thickness in a trochoidal hydrostatic gear pump," In: Proceedings of the Institution of Mechanical Engineers, Part $G$ : Journal of Aerospace Engineering, vol. 218, no. 4, pp. 247-256, 2004.

[27] Z. Xu, D. Gong, and J. Zhao, "Optimal processing method of hybrid bearing oil wedge," Manufacturing Technology \& Machine Tool, no. 5, pp. 115-116, 2012. (in Chinese with English abstract).

(C) Zhenxing et al.; Licensee Bentham Open.

This is an open access article licensed under the terms of the Creative Commons Attribution Non-Commercial License (http://creativecommons.org/licenses/by-nc/3.0/) which permits unrestricted, non-commercial use, distribution and reproduction in any medium, provided the work is properly cited. 